\title{
ALAT BANTU SISWA UNTUK MENGEKSPLORASI LINGKUNGAN SEKITAR DALAM APLIKASI BSE \\ Putri Yuliani' ${ }^{1}$, Rizqi Taufiq Febrian Ashar ${ }^{2)}$ \\ ${ }^{1,2)}$ Program Studi Teknik Informatika \\ Universitas Muhammadiyah Malang \\ Jalan Raya Tlogomas No. 246, Tlogomas, Lowokwaru, Malang, Indonesia \\ e-mail: pyyuliani@gmail.com ${ }^{1}$, akatsukirizqi@gmail.com $^{2)}$
}

\begin{abstract}
ABSTRAK
Tujuan penelitian ini adalah untuk menganalisa rancang bangun dari aplikasi Buku Sekolah Elektronik yang bertemakan Observasi Lingkunganmu. Buku Sekolah Elektronik adalah buku elektronik yang dapat diunduh di beberapa website. Buku Sekolah Elektronik saat ini hanya berupa buku berformat *.pdf yang hanya bisa dibaca dan dicetak. Buku Sekolah Elektronik sebenarnya dapat dimaksimalkan fungsinya agar siswa tidak hanya membaca saja, tetapi dapat melakukan beberapa aktivitas di dalam Buku Sekolah Elektronik, seperti mengerjakan latihan soal, menandai halaman atau kata-kata yang penting, bercerita dan memotret lingkungan sekitar. Tujuannya dibuat aplikasi Buku Sekolah Elektronik ini adalah agar siswa dapat lebih aktif lagi, karena saat ini Indonesia menggunakan kurikulum 2013, dimana siswa dituntut agar lebih aktif dalam kegiatan belajar mengajar, juga agar meningkatkan kemampuan siswa khususnya dibidang observasi dan bercerita. Dalam menganalisis sistem ini, peneliti melakukan penggalian kebutuhan dengan membuat beberapa diagram UML (Unified Modeling Language), diantaranya adalah use case, use case scenario, dan activity diagram juga mock up yang sudah dibuat. Hasil dari penelitian ini berupa diagram UML dan prototype berupa mock up dari aplikasi Buku Sekolah Elektronik. Peneliti selanjutnya diharapkan bisa melanjutkan penelitian ini ke tahap selanjutnya, yaitu menentukan metode pengembangan yang akan digunakan, dan lain sebagainya.
\end{abstract}

Kata Kunci: analisis perancangan, aplikasi, buku sekolah elektronik, unified modelling language.

\section{Pendahuluan}

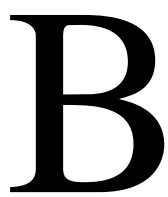

UKU sekolah elektronik adalah salah satu media pembelajaran yang sudah cukup lama digunakan di Indonesia. Namun pada penerapannya, buku sekolah elektronik hanya berformat *.pdf yang hanya bisa dibaca dan dicetak saja. Tidak ada interaksi timbal balik antara siswa dengan buku. Buku sekolah elektronik disebut sebagai buku elektronik hanya karena didapat dengan cara mengunduh buku dari internet. Kurangnya fungsionalitas buku ini mengakibatkan hanya sedikit pengguna yang benar-benar membaca buku ini. Sebenarnya, buku sekolah elektronik dapat dikembangkan agar pengguna bisa berinteraksi dengan buku elektronik terserbut.

Maka dari itu, dengan dibuatnya aplikasi buku sekolah elektronik ini diharapkan agar para pengguna betah dalam menggunakan buku sekolah elektronik ini sebagai media pembelajaran mereka. Fitur yang digunakan di dalam aplikasi ini antara lain; menu membaca yang didalamnya ada fitur bookmark, highlight, dan search, dan zona observasi. Zona observasi berfungsi agar siswa dapat mengobservasi dan bercerita tentang lingkungan sekitarnya. Selanjutnya ada menu latihan soal, di sini pengguna bisa menjawab soal yang sudah disediakan sebelumnya. Soal yang disediakan berupa pilihan ganda.

Buku elektronik yang kami analisis ini adalah buku kelas 5 SD dengan tematik 3 (Lingkungan Sahabat Kita) dan tematik 2 (Benda-Benda di Lingkungan Sekitar). Kedua buku ini fokus kepada tema lingkungan sekitar, baik terhadap benda hidup dan benda mati.

Siswa diharapkan bisa mengenal lingkungannya lebih dekat dan lebih baik dengan cara mengobservasi dan memperhatikan lingkungan disekitarnya, baik itu ekosistem di lingkungannya, tatanan masyarakat yang ada, peran dalam keluarga, dan lain sebagainya. Jika siswa sudah dapat mengobservasi dan meneliti lingkungan sekitarnya, siswa selanjutnya diharapkan bisa bercerita mengenai lingkungannya tersebut. Cerita tersebut bisa dalam bentuk hasil ketikan, hasil tulis tangan yang kemudian di-scan atau hasil potret dari lingkungan sekitarnya. 


\section{METODOLOGI PENELITIAN}

\section{A. Alur Penelitian}

Metodologi penelitian yang digunakan adalah:

1. Mengidentifikasi Masalah

Peneliti mengidentifikasi permasalahan apa yang ada sehingga penelitian nantinya akan lebih jelas dan terarah.

2. Pengumpulan Data

Dalam mengumpulkan data, penulis menggunakan metode studi pustaka untuk mengumpulkan data. Studi literature meliputi membaca buku bacaan, literature, jurnal, dan lain-lain yang sesuai dan relevan dengan permasalahan yang diangkat.

3. Analisis Sistem

Peneliti menggunakan unified modelling language (UML) untuk menggambarkan interaksi di dalam sistem. Peneliti menggunakan use case diagram, activity diagram, dan sequence diagram untuk menganalisis sistem ini.

4. Perancangan Sistem

Dalam perancangan sistem, peneliti menggunakan prototyping untuk menggambarkan proses antarmuka di dalam system. Menurut Kenet E.Kendal dan Julie E.kendal : $(2010$; 221) Prototyping adalah suatu teknik yang sangat rumit karena memerlukan pengetahuan mengenai siklus hidup pengembangan sistem secara keseluruhan.

\section{B. Bahan Penelitian}

Bahan yang digunakan peneliti dalam penelitian ini adalah buku sekolah elektronik yang diunduh melalui website bukusekolahdigital.com.

\section{Alat Penelitian}

Alat yang digunakan dalam penelitian ini adalah seperangkat komputer dan alat-alat pendukung.

1. Spesifikasi computer yang digunakan pada penelitian ini adalah:

- Computer : Laptop

- Processor : Core i5

- $\quad$ RAM $\quad: 4 \mathrm{gb}$

2. Spesifikasi software yang dibutuhkan:

- System operasi : Windows 10

- DBMS : MySQL

- Bahasa Pemrograman : Java

- Tools : Star UML, JustInMind

- Dan beberapa perangkat lunak pendukung lain.

\section{Kebutuhan Fungsional}

- Siswa dapat membaca buku sekolah elektronik.

- Siswa dapat melakukan pencarian dengan kata kunci tertentu.

- Siswa dapat menandai halaman yang diangap penting.

- Siswa dapat menandai kata-kata penting.

- Siswa dapat mengerjakan soal latihan.

\section{E. Kebutuhan Non Fungsional}

- Sistem dapat diakses 24 jam.

- Tampilan yang user friendly.

- Sistem mudah digunakan.

- Membutuhkan internet untuk mengakses system ini. 


\section{F. Fitur Khusus}

- Sistem menyediakan fitur Observasi Lingkungan

\section{HASIL DAN PEMBAHASAN}

Proses yang terjadi pada sistem digambarkan dengan menggunakan diagram UML yaitu Use Case Diagram, Activity Diagram, dan Sequence Diagram. Prototype dari system ini juga akan dipaparkan di bawah ini. Di sini, peneliti hanya memaparkan sebagian kecil dari diagram UML yang ada. Adapun diagram dan prototype untuk dapat dilihat pada gambar di bawah ini:

a. Use Case

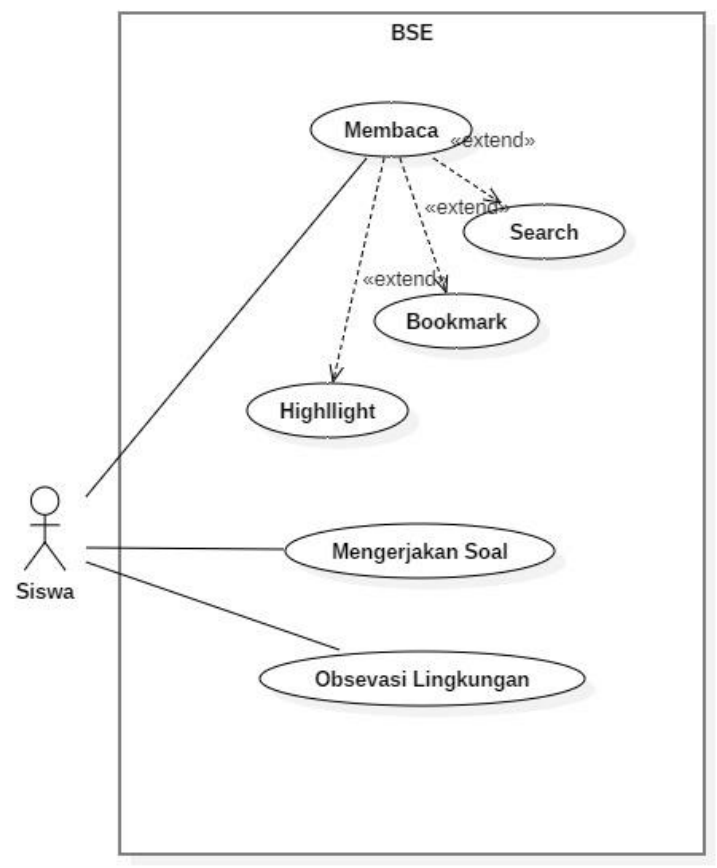

Gambar. 1

b. Activity Diagram

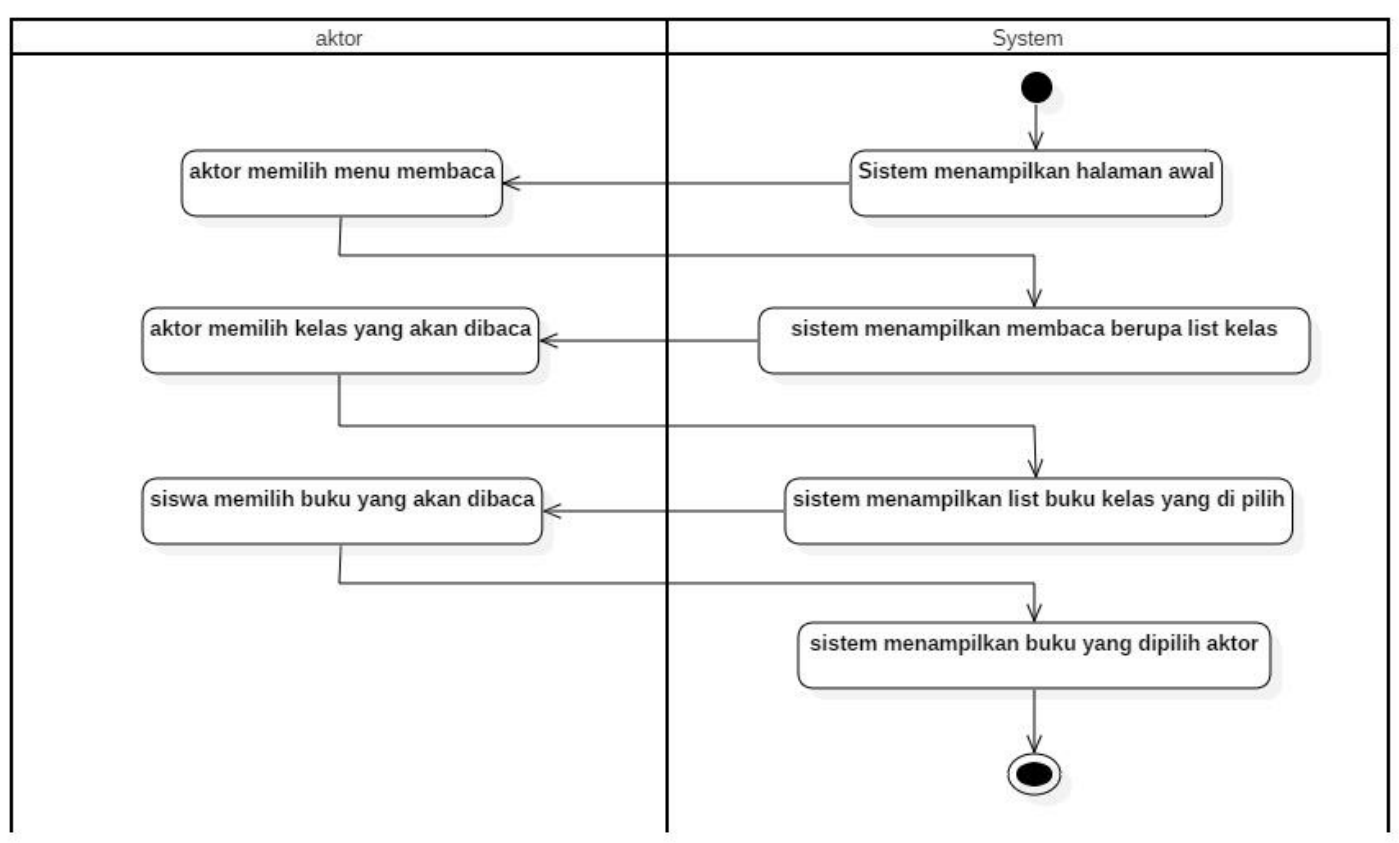




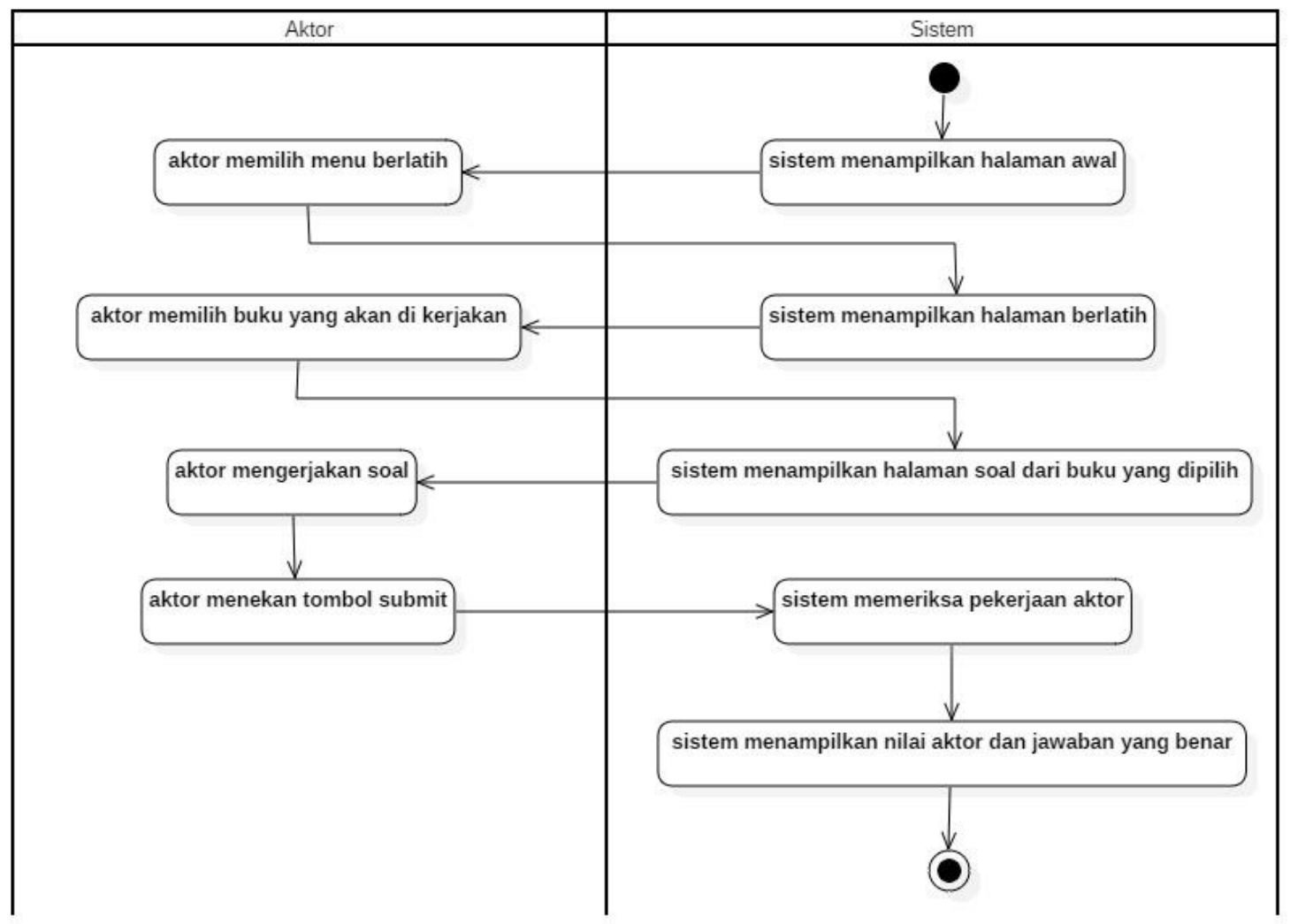

Gambar. 3 Activity Diagram "Mengerjakan Soal"

\section{c. Sequence Diagram}

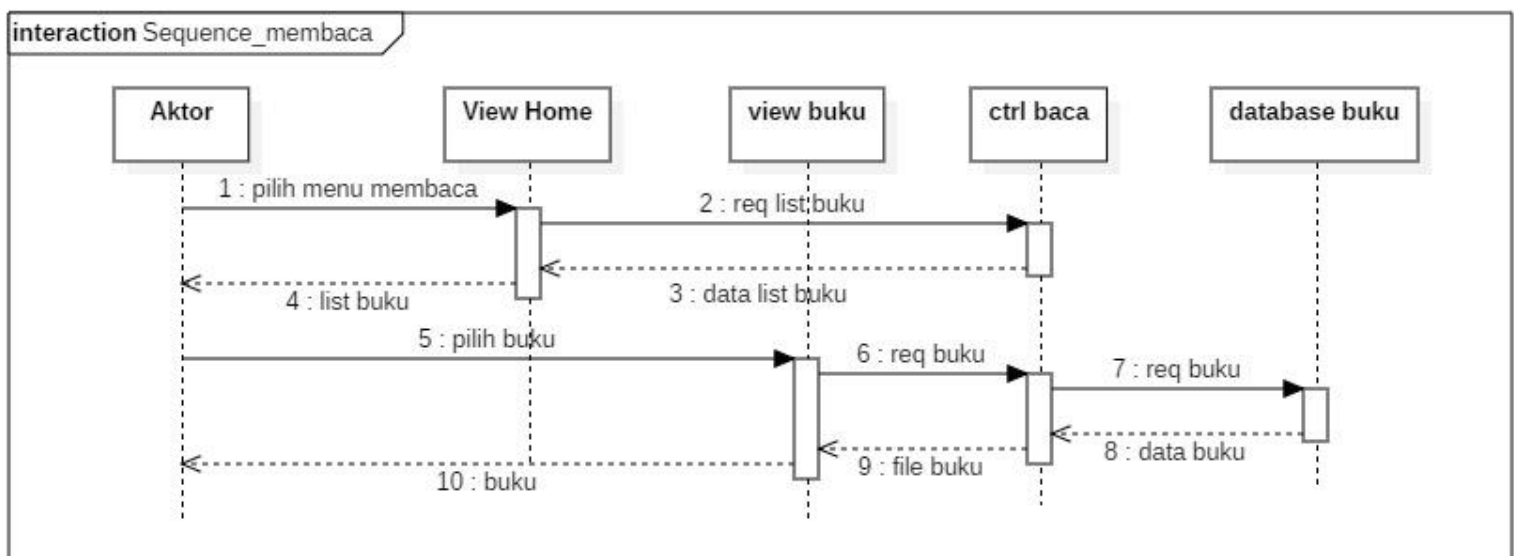

Gambar. 4 Sequence Diagram "Membaca" 


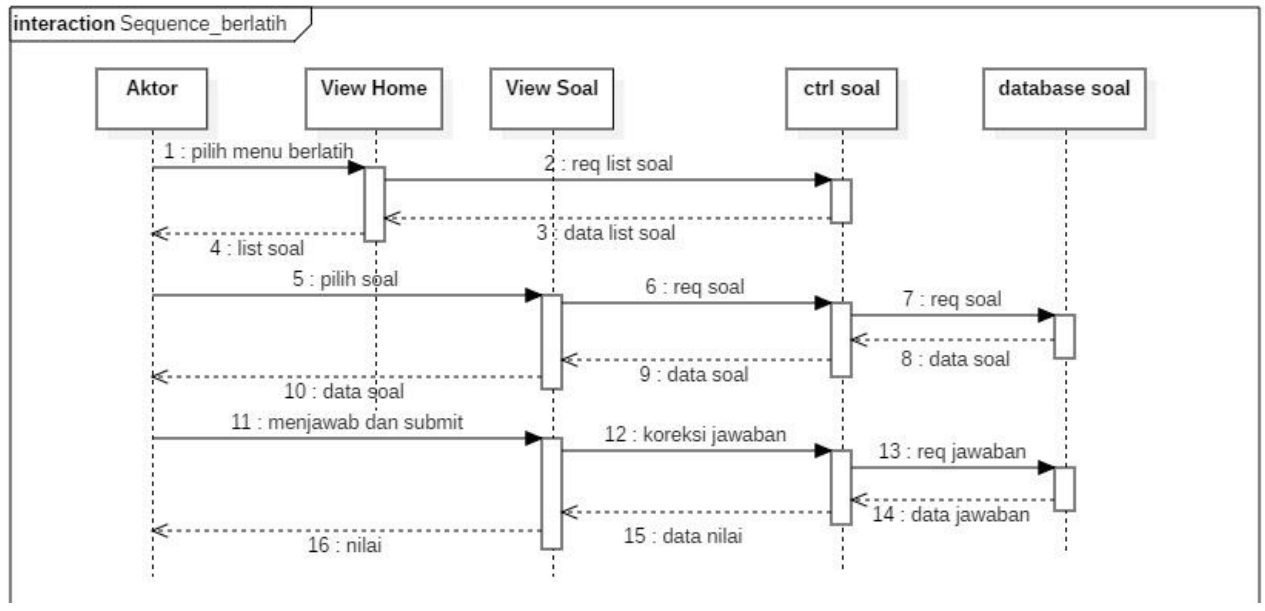

Gambar. 5 Sequence Diagram "Mengerjakan Soal"

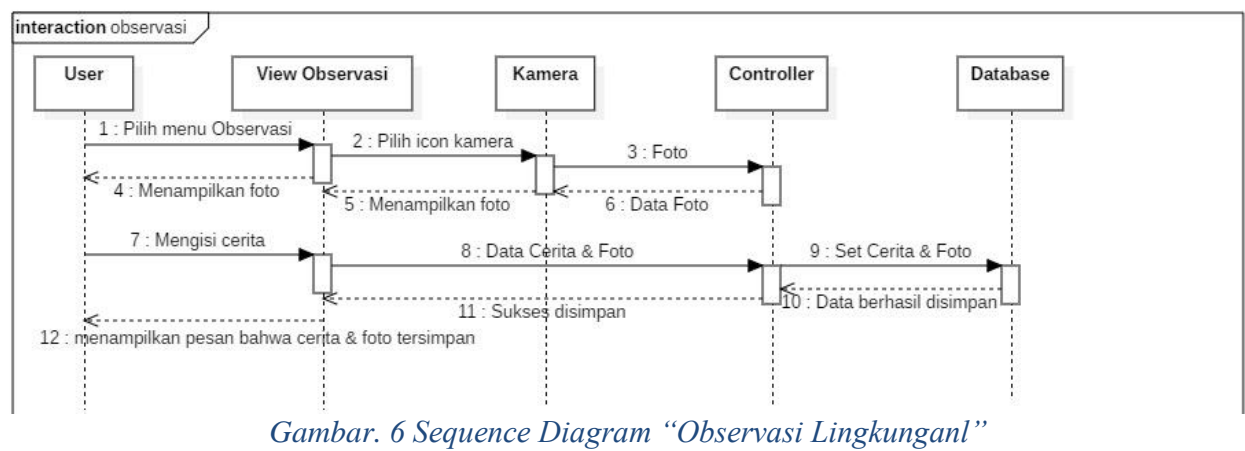

d. Prototype

- Gambar. 7 menampilkan halaman utama pada aplikasi buku sekolah elektronik yang menunjukkan fitur-fitur utama di dalam aplikasi ini. Ikon biru berlambang orang di kanan atas adalah tombol profil.

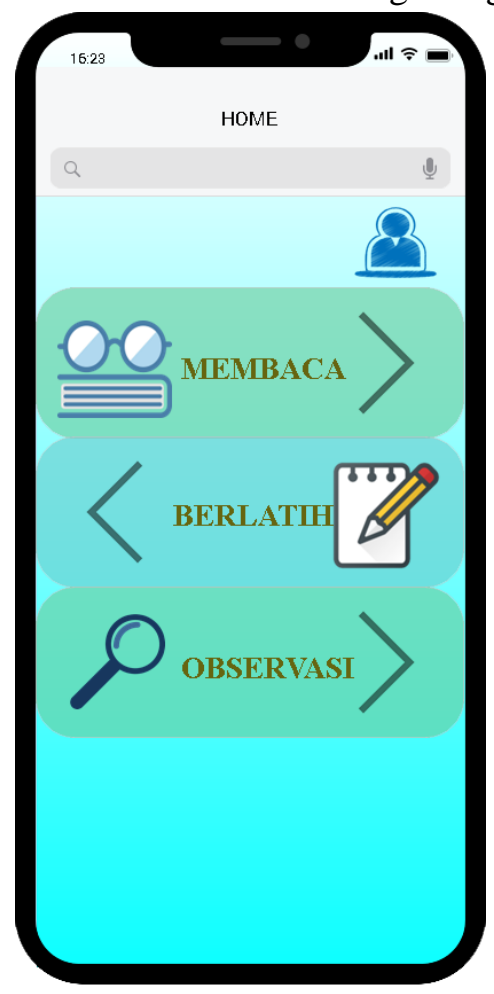

Gambar. 7 Halaman Utama 
- Gambar. 8 menampilkan saat buku sudah dibuka. Buku ini adalah yang sebelumnya berformat *.pdf.

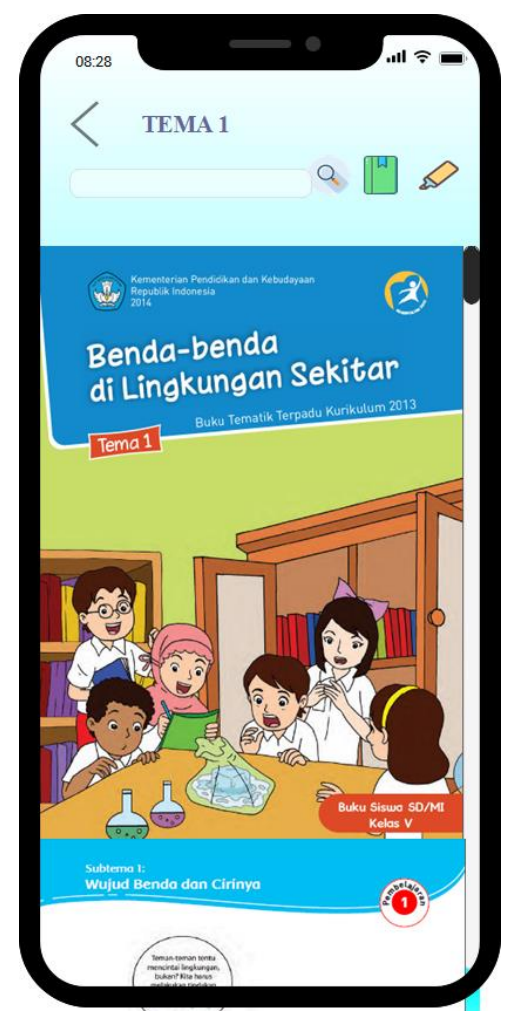

Gambar. 8 Halaman Buku

- Gambar. 9 menunjukkan saat soal sudah dibuka. Siswa bisa memilih satu jawaban yang dirasa paling benar. Di bawah halaman soal, terdapat tombol submit yang berfungsi agar system bisa mencocokkan jawaban siswa dengan jawaban yang sebelumnya sudah disimpan di database.

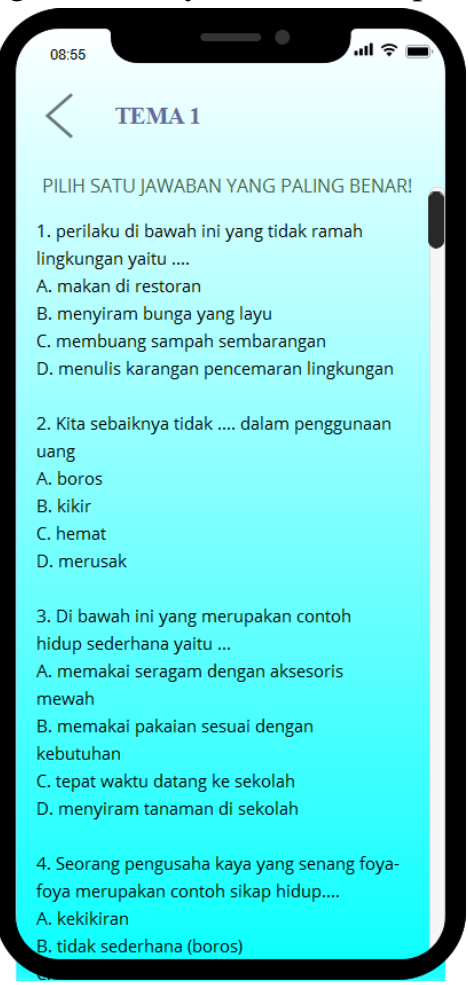

Gambar. 9 Halaman Menu Latihan Soal 
- Gambar 10 menunjukkan halaman observasi dimana siswa bisa mengambik gambar lingkungan sekitar dan menceritakan lingkungannya melalui text box yang telah disediakan.

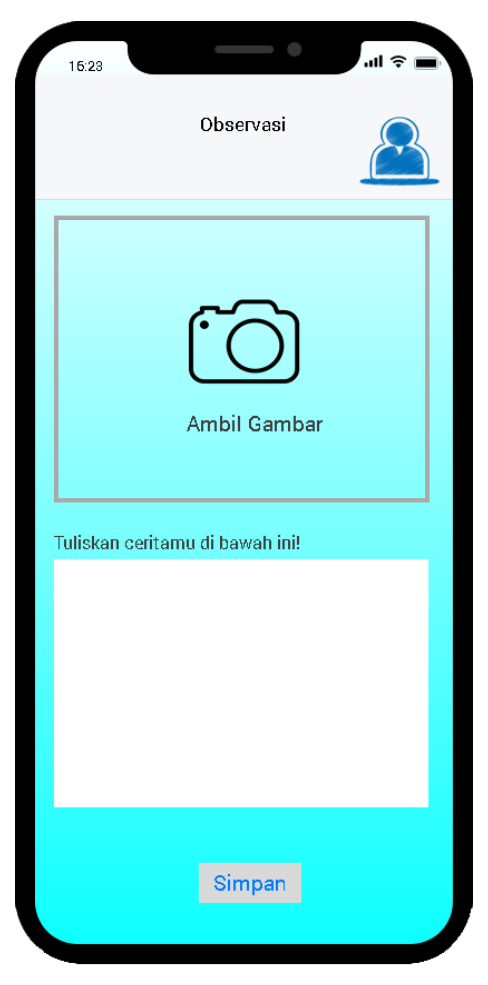

\section{KESIMPULAN DAN SARAN}

\section{A. Kesimpulan}

Berdasarkan hasil penelitian kami, maka dapat kami simpulkan bahwa:

1. Aplikasi Buku Sekolah Elektronik ini dapat dijadikan salah satu pilihan sebagai media belajar siswa karena fitur dan fungsionalitasnya cukup lengkap

2. Aplikasi Buku Sekolah Elekronik ini disusun dan dirancang secara sederhana agar mudah digunakan oleh user, dimana user adalah siswa SD.

3. Dengan adanya fitur observasi, siswa dapat memotret dan bercerita tentang keadaan lingkungannya.

B. Saran

1. Soal dalam menu Berlatih hanya berupa pilihan ganda. Diharapkan kedepannya pengembang dapat menambah varian soal.

2. Disarankan kepada peneliti selanjutnya agar menambah aktor guru, dimana guru dapat memantau perkembangan murid yang menggunakan aplikasi ini.

\section{REFERENCES}

Hilman, S. (2016). Perancangan Program Aplikasi Transaksi Pembayaran SPP, UTS, dan UAS Menggunakan Metode Analisis dan Desain Berorientasi Objek Model Unified Approach (UA). Garut: Sekolah Tinggi Teknologi Garut.

Mathiassen, L. (2000). Object Oriented Analysis and Design. Denmark: Marko.

Safaat, N. (2012). Pemrograman Aplikasi Mobile Smartphone dan Tablet PC Berbasis Android. Bandung: Informatika.

Susilowati, M., \& Prasetija, H. P. (2016). Analisis dan Desain Berorientasi Objek pada Sistem Informasi. Seminar Nasional Ilmu Komputer, 161-168.

Wati, T. R., \& Sismoro, H. (2009). Analisis dan Perancangan Aplikasi Android. Seminar Nasional Aplikasi Teknologi Informasi, 93-100. 